5

\title{
Wolves' Tongues and Mercury: Pharmaceutical Cures for Cancer
}

Early modern patients diagnosed with cancer were positioned at the centre of debates about gender, the nature of disease, anatomy and the humours. More practically, they also found themselves with a malady that was often painful and disfiguring and had the potential to end their lives. Confronted with such an illness, what was to be done? The following two chapters examine how cancer sufferers, and the medical practitioners who attended to them, attempted to stem or reverse the effects of this disease. I will argue that, in their most potent forms, cancer treatments continued the conceptual separation of patient from disease which was visible in zoomorphic and anthropomorphic descriptions of cancer's character. In so doing, they diminished the patient's role in their own cure, while foregrounding an adversarial relationship between medical practitioners and 'rebellious' cancerous tumours. Throughout the early modern period, cancer treatments provoked fierce debate over both the nature of disease and the proper limits of medical intervention.

In this chapter, I investigate non-surgical therapeutics for cancer. These are loosely defined as those remedies which did not involve the dreaded 'Knife or fire' in cutting or otherwise penetrating the flesh (though as I shall show, this did not mean that such remedies could not cause fissures, intentional and otherwise, in the patient's skin). ${ }^{1}$ Such 'cures' were incredibly varied, ranging from strict diets, to unguents such as oil of frogs (made by baking the creatures with butter in their mouths), to powerful purges of hellebore or senna, and toxic caustics including arsenic and mercury. ${ }^{2}$ They were also employed by diverse parties: although surviving sources primarily document those cures prescribed by professional medical practitioners, many empirics, apothecaries and lay people had their own opinions on how best to cure a cancer. Despite 
the apparently disparate nature of these materials, a thread can be traced through cancer therapeutics. Prescriptions can roughly be graded, as I have divided them here, into orders of severity, from the merely unpleasant, to the acutely dangerous, with the most radical therapies accompanied by elaborate rhetoric and impassioned debate. Departing from treatments based on regimen and rebalancing the humours, which involved the active participation of the patient, increasingly complex and potent pharmaceutical interventions focussed less and less on the individual with cancer, and foregrounded the zoomorphised or anthropomorphised tumour. At length, therefore, both medical practitioners and patients faced a decision: in order to kill a cancer, how far were they willing to go?

The most comprehensive look at early modern cancer treatments is currently provided by Marjo Kaartinen's Breast Cancer in the Eighteenth Century, and the medical landscape that text describes is in many respects similar to the one I explore in this chapter. ${ }^{3}$ Kaartinen notes, for example, the continuity of lay and 'professional' therapies for cancer and the incomplete distinction of curative from palliative remedies. ${ }^{4}$ Moreover, it is clear that many of the therapies employed in the eighteenth century were ones which remained unchanged over several hundred years, even dating back to the medieval period. Receipts made from ingredients such as plants, animal dung and grease were passed down in domestic receipt books and through printed texts of various kinds from the sixteenth into the eighteenth century. ${ }^{5}$ Likewise, lead and mercury waxed and waned in popularity as cancer cures, but remained in use for well over three hundred years. ${ }^{6}$ In other aspects, however, it is clear that the later eighteenth century in particular was characterised by a preponderance of exotic cures for cancer with no equivalent in earlier texts, including the ingestion of lizards, use of electrical therapy, and application of carbonic acid to tumours. ${ }^{7}$ These innovations evidently depended on alterations in medical theory, and in socio-economic circumstances, which were unique to the later reaches of the early modern period. Aside from Kaartinen's study, early modern treatments for cancerous disease have seldom been investigated at any length. In her Female Patients in Early Modern Britain, Wendy D. Churchill briefly describes the way in which women with breast complaints often delayed seeking medical attention until pain or debility made it absolutely necessary, fearing the painful methods of 'cure' offered by both physicians and surgeons. ${ }^{8}$ Luke Demaitre's essay on cancer in the medieval period also notes the reluctance of medical practitioners to interfere with cancers, as well as the particular use of prescriptions from the Dreckapothecke - that is, various 
kinds of excrement. ${ }^{9}$ In his lengthy study of the history of cancer therapeutics, Siddhartha Mukherjee evocatively characterises early modern cures for cancer as 'an intricate series of bleeding and purging rituals to squeeze the humours out of the body as if it were an overfilled, heavy sponge'.$^{10}$ However, these works have paid relatively little attention to the way in which remedies for cancer reflected beliefs about the nature of the disease, or medical practitioners' relationship to the malady.

This chapter also looks to scholarship on other, more studied, diseases in order to contextualise some of the methods and ingredients employed in the treatment of cancer. In particular, works on venereal pox have provided valuable details about the unpleasant side-effects of mercury 'cures' which may help to explain why this course was such a controversial one in the treatment of cancer. ${ }^{11}$ As noted in the Introduction to this book, recent scholarship has also foregrounded the protean nature of the early modern medical marketplace. Iatrochemical methods were, as I discuss, incorporated into medical systems which remained broadly humoralist in both theory and praxis. ${ }^{12}$ Likewise, the differentiation between varieties of medical practitioners - physicians, surgeons, apothecaries and itinerant medicine-sellers among others - was often problematic. Particularly outside London, the line between authorised and 'empiric' practice, as well as between areas of specialisation, was blurred. Patients might pick and choose from a broad range of practitioners depending on their budget, complaint, locale and personal preference. ${ }^{13}$

The methods by which medical practitioners attempted to treat cancer were diverse, complex and, in many cases, incompletely recorded. With many medical textbooks listing multiple cures, it is likely that more than one avenue of therapy was pursued at any one time, so that, for example, a patient might undergo purging, apply daily salves or lotions, and maintain a modified diet, more or less simultaneously. Broadly speaking, however, it is clear that many early modern patients and medical practitioners subscribed to the intuitive approach of beginning treatment with mild therapies, and moving on to increasingly violent ones if the disease failed to respond. This is the schema upon which the chapter is divided, and along which I trace a corresponding conceptual shift leading to the exclusion of the patient, as an individual and an agent in their own recovery, from a drama played out between medical practitioners and cancer.

The first section of the chapter therefore discusses recommendations for the regimen of the cancer sufferer - their diet, the administering of medicinal purges to expel excess humours and bloodletting. Such 
prescriptions, I argue, were based on an understanding of the disease as humoral in origin and emphasise the responsibility of the patient for their own physical well-being. The second section looks to internal medicaments, unguents and salves which were specific to cancer. Such therapies increasingly treated cancer sufferers as interchangeable, becoming more invested in combatting cancer as an ontologically independent complaint. In the third section, I look at those medicines - usually applied to ulcers and tumours on the body's surface - with corrosive properties, primarily arsenic and mercury. Unpleasant, and frequently dangerous, such therapies were highly controversial, but, tantalisingly, seemed to promise an 'eating' force to rival that of the malignant tumour.

\subsection{You are what you (don't) eat? Combatting cancers with diet and regimen}

On an unrecorded date in the mid-seventeenth century, the physician John Fernelius wrote to his colleague Simon Pietre for advice regarding a tricky case of 'cancerous wenns' in the armpit of a young woman. ${ }^{14}$ Pietre's reply tells us much about the way in which medical practitioners approached this disease, and is worth citing at length. The letter began with a brief recipe for ointment to be applied to the wens (sub-dermal lumps), with a warning against using any strong medicines. The bulk of the letter, however, was taken up with detailed instructions for the woman's regimen, which, Pietre argued, ought to include regulation of diet, medicinal purges and bloodletting:

the whole body of this ingenuous damosel... is tender and dry, as I understand by her Father, it must be gently handled. And therefore it must be purged with Cassia Fistula, Diacatholicon, or King Sapors syrup newly made, half the saffron being left out. Which let her take twice or thrice in a month, with whey wherein Epithymum and fumitory have been infused. And because her nature seems inclined to breed melancholick juice, even of the best meats, through fault of her Livers distemper; we must fight against that juice with a syrup made of juice of bugloss, Borage, Caume, Endive, sweet prunes, whereof let her take amornings with boyled water. To the same intent Asses milk will be good, which let her use every morning with a little sugar. At the approach of spring and Fal, her body being purged, let her left basilica or median veine be opened, and take two smal porringers of blood. Finally, make an issue in her left Arme, neare the muscle Deltois. This summer time let her frequently use a bathe of sweet 
fresh water, to correct the driness of her body. Moreover, let an opiate be made for her of Conserve of Violets, Lillies, Roses, Bugloss, Borrage, Citron peel, Confectio alkermes, that by the use thereof the malignant force of the melancholy juice may be amended and the patients natural strength restored.

Let all her diet and course of life tend to moistness, and moderately to cool; refusing all meats that breed melancholick juice.

Let her use ptisan [tisane] instead of wine, or a decoction of coriander with Raisons. And when the heat of the weather shall be more remiss, you shall order her wine well allaid with water, which in this extremity of summers heat I do not allow. ${ }^{15}$

Pietre's recommendations found favour with Fernelius, who saw fit to include them in his 1662 Select Medicinal Counsels. Moreover, they reflected precisely the belief of many contemporary practitioners: that cancer was a disease with humoral origins, which might be cured by redressing bodily imbalance.

Widely believed to have its origins in humoral dysfunction - namely, the burning or stagnation of black bile - cancer represented an ideal candidate for redress by adjustment of the 'non-naturals', diet and bodily regimen. In turn, regulation of non-naturals was perhaps the most widespread form of medical prescription during the early modern period, and, as Andrew Wear has observed, an idea firmly embedded in the nation's cultural consciousness. ${ }^{16}$ Insightful work has lately been written on the importance of regimen in neo-Galenic therapeutics. Jan Purnis, for example, argues in 'The Stomach and Early Modern Emotion' that attention to diet reflected a 'profoundly embodied partnership' between body and mind in early modern somatic experience. ${ }^{17}$ Margaret Healy similarly observes that '[i]t is probably true to say that the maxim, "We are what we eat", was never so significant in England until this period', with adherence to certain dietary rules deemed essential for the spiritual and physical health of both individual and country. ${ }^{18}$ In his 2002 Eating Right in the Renaissance, Ken Albala approaches the relationship of food and medicine from the opposite direction, arguing for a sincere, if sometimes confused, interest in the medicinal effects of food from culinary writers across Europe. ${ }^{19}$ While scholars have investigated the early modern relationship between food and medicine from different perspectives - indeed, a comprehensive work on food as medicine in this period has yet to be written - they are in agreement on two points; both of which, I will contend, are highly visible in texts dealing with cancer. They concur that 
drinks and foodstuffs were thought of as having heating, cooling, moistening or drying properties, by which they could create or redress humoral imbalance in the consumer. Moreover, they argue, this direct connection between eating and being temperate or intemperate cast food as a mode of self-determination with intertwined moral and physical consequences.

We have seen in Chapter 1 that cancer was most often conceived of as a disease of atra bilis, a noxious derivative of the melancholy humour. In their advice on the most appropriate diet and regimen to counteract or prevent cancers, medical practitioners varied little across 150 years, returning repeatedly to the recommendations of moderation and avoidance of 'strong' meats found in Galen's Methodus Medendi as a means to quell excess melancholy. ${ }^{20}$ In 1583, for example, Philip Barrough advised that 'among other thinges this is chiefly and principally to be observed, (namely) that such nourishment be given to the diseased, as have vertue to refrigerate and moysten, and which doe engender good and slender juyce'. ${ }^{21}$ He went on to specify 'fishes of gravelly places', egg yolks and poultry (excepting that which 'live in fenny groundes') as particularly desirable foodstuffs, his descriptions demonstrating the remarkable specificity with which gamey meats or sea fish were distinguished from their lighter counterparts. ${ }^{22}$ The foods Barrough prescribed were believed to be cool and moist in quality; meals thought not to tax the digestive system, and, perhaps, ways to tempt a sickly appetite. In this the physician conformed to Galen's advice that melancholy individuals should 'use meats that are light of digestion' ${ }^{23}$

This injunction was heeded over and over by medical practitioners from the sixteenth to the eighteenth century. A 1698 edition of The Compleat Midwife's Practice, for instance, advised a diet of 'cooling and moistening spoon-meats' for any woman with inflamed breasts that might turn cancerous, while other writers prescribed spare and bland food and drink. ${ }^{24}$ Any reader confused as to the components of a 'spare' or 'cooling' diet could turn to those, like Ambroise Paré, who decreed in detail which foods a cancer sufferer might safely eat, and which should be avoided:

thicke and muddy wines, vinegar, browne bread, cold hearbes, old cheese, old and salted flesh, Beefe, Venison, goate, hare, garlicke, onions and mustard, and lastly all acride, acide and other salt ... which may by any meanes incrassate [thicken] the blood, and inflame the hum[ours]... be eschewed. A cooling \& humecting diet must be prescribed; fasting eschewed, as also watchings, immoderate labours, sorrow, cares, and mournings; let him use ptisans, and in his brothes 
boile Mallowes, Spinach, Lettuce, Sorrell, Purslaine, Succory, Hops, Violets, Borradge, and the foure cold seeds. But let him feede on Mutton, Veale, Kid, Capon, Pullet, young Hares, Partridges, Fishes of stony rivers, reare Egges; and use white wine, but moderately for his drinke. $^{25}$

Paré's injunction against red meats and strong savoury flavours in favour of white or 'young' meat, green vegetables and fish was typical among his contemporaries. The caution given here against 'thicke and muddy wines' was also commonplace, with Alexander Read later asserting that 'there is nothing more pernicious [for melancholy complexions] than the immoderate use of potent and strong wines, such are all kinds of Sacks, and greeke wines, which exceedingly burne the humors in the masse of the bloud'. ${ }^{26}$ Such prescriptions followed the logic of humoral theory to the letter. Moist meats and broths, for example, were believed to counteract the dry melancholy humour which led to the stagnation of blood, and the separation of noxious properties within the blood which 'resembleth the dregges of wine'. ${ }^{27}$ Meanwhile, warnings against the evils of excessively strong liquor drew on the advice in Galen's Methodus Medendi that a person of choleric complexion should 'fly from Wine and strong Beer as fast as he would fly from a Dragon' ${ }^{28}$ The emphasis placed on avoiding strong alcoholic drinks in texts on cancer thus demonstrates the degree to which choler was felt to be implicated in the transformation of melancholy into atra bilis, which in many texts appeared as a process of burning or 'adustion'.

Most dietary recommendations had their roots in Galenic theory and were justified in those terms. However, they also incorporated a degree of moral proscription, resting as they did upon patients' everyday choices around food, drink and physical activity. In her article on 'Sciences of Appetite' in the eighteenth century, Elizabeth A. Williams argues that 'seventeenth-century medical advice was marked by eating anxieties and by medical antagonism toward gastronomic indulgence' ${ }^{29}$ The red meat, strong cheeses and potent wines described as causing cancers fell into that category of 'indulgences', and only the wealthy could afford to eat such items regularly. In particular, medical writers repeatedly identified foreign, especially Greek, wines as dangerous to health, recommending instead watered-down wine or small beer. ${ }^{30}$ Indirectly, they thus linked cancer to epicurean or intemperate appetites, seemingly remaining oblivious to the fact that those who could afford their services were by definition likely to be among those few who enjoyed a rich, varied diet. In addition - as so often in discourses about the disease - women 
were once again marked out as particularly vulnerable. As described in Chapter 2, large breasts, as associated with obesity, were viewed as a risk factor for breast cancer. Women were understood as likely to have more body fat than men because of their more sedentary lifestyles, their lack of self-mastery, which led them to over-eat, and their cold humours, which were inadequate to fully concoct, or 'burn off', rich meals. ${ }^{31}$

As Healy states in 'Bodily Regimen', 'staying healthy had enormous spiritual and moral implications' in this period, in which 'disease had become a culpable and blameworthy affair closely associated with overindulgence'. ${ }^{32}$ Where lifestyle prescriptions for staying or curing cancer extended their reach beyond diet, this moral dimension became even more pronounced. In accordance with Galen's recommendations for choleric complexions, writings on cancer repeatedly warned against strenuous exercise. ${ }^{33}$ Exercise could seldom be considered immoral in itself, though it might be less than genteel. However, many medical practitioners extended that proscription to include mental and emotional 'labours', which one had a duty to try and moderate. In 1650, for instance, Read echoed the advice of many of his contemporaries when he advised that 'watching [brooding], immoderate labour and griefe' should be shunned by cancer patients, since, like certain foods, they heated the body and facilitated the creation of atra bilis. ${ }^{34}$ As discussed in Chapter 2, when viewed alongside the belief that blows or bruises could bring on cancers, such speculation on the dangers of grief and anger takes on a darker perspective, in which spousal violence is tacitly indicated as one way of generating this disease. Not only were women most likely to be the victims of such violence, it was also believed that they had difficulty in controlling their emotions, making them, once again, more vulnerable to the ill effects of melancholy.

Readings of cancer which positioned diet and regimen as crucial to one's chances of surviving the disease might be read as disempowering. One might naturally have a melancholic or choleric disposition which was particularly susceptible to heating by unsuitable foodstuffs. Equally, a hostile home environment, bereavement or other outside factors might bring on the harmful 'watching' and grief which exacerbated the disease - not to mention the fact that 'immoderate labour' was not a matter of choice for many early modern patients. Yet while cures which emphasised the need to balance the humours highlighted certain circumstantial or physical predispositions to cancer, they also stressed the connection between moral, psychological and physical health, and offered opportunities for holistic self-determination - namely, the chance to heal oneself. So firmly was this belief engrained in the mind 
of medical practitioners that some writers recorded great frustration with patients who neglected their prescribed regimen. Writing in 1711, William Beckett complained: 'I cabbit [cannot] say whether I had more trouble with the Cancer, or in endeavouring to oblige my Patient to a strict Observance of some of the non-Naturals she so often err'd in' ${ }^{\prime 35}$ Repeating the age-old grievance of medical practitioners, he bemoaned patients 'nor taking so much Care of themselves, as they expect that the Surgeon should take of 'em'. ${ }^{36}$

Despite their occasional obstinacy, by careful regulation of diet, and procedures such as purging and phlebotomy, cancer patients could, it was believed, evacuate corrupt matter from the body, redress their faulty humours and help themselves to become healthy again. As such, concoctions designed to purge the whole body of excess humours were a staple of almost every printed medical text and appear as a natural progression from the regulation of the body through food and exercise. A 1662 translation of Lazarus Riverius's medical observations, for example, emphasised the importance of purging before any other avenues of cure were to be pursued, and even proposed that purges could completely cure an incipient cancer:

where speaking of a Cancer, [Galen] has these words. I have often Cured this Disease when it was but beginning, but when it is grown large, it cannot be cured without manual operation; and a little after: this disease I have (as was said) Cured at the beginning, especially when the melancholy humor was not very thick; for then it easily gives way to purging Medicaments, by which the Cure is effected; and it is easie to conceive, that these purging Medicaments must purge black choler ... Herefore I conceived I must fly to the use of strong Remedies, the chief of which is the Root of black Hellebore, which is most effectual to purge Melancholly. ${ }^{37}$

Black hellebore was a favourite purgative for Riverius; a 1655 translation of the author's The Practice of Physick again asserted that 'by giving the Extract thereof twice or thrice, we have somtimes cured a Cancer in the beginning ${ }^{\prime}{ }^{38}$ Medical practitioners throughout the early modern period placed similar store by the effectiveness of this poisonous substance, often combining it with gentler ingredients such as senna, rhubarb and endives in a broth or tisane. ${ }^{39}$ While purges might be less toxic than the concoctions of arsenic and mercury favoured by some physicians, however, they could hardly be considered an easy option. Senna was well known as a laxative, and hellebore was a powerful emetic, potentially lethal in the wrong hands. In this light, Riverius's repeated emphasis 
on purging the body takes on extra emotional importance. The cancercausing atra bilis was 'conceived' as something more than mere chemistry, appearing instead as a malign progeny to be driven from the body, and the discomfort of purging was recast as a personal 'labour' by which such mal-productions might be expelled. ${ }^{40}$

In the related process of bloodletting, expulsion of ill humours from the body was similarly positioned as an exercise to heal while it hurt. Removing harmful atra bilis, and often standing in for interrupted menstrual or haemorrhoidal bleeding, bleeding appeared as a positively intuitive response to illness for a variety of medical practitioners and their patients. Riverius, for example, suggested bleeding 'in the Arm, Anckle, and Hemorrhoid Veins' as an effective means to stay, if not to cure, cancers of the womb, while John Browne believed that judicious bleeding could stay cancers in any part of the body. ${ }^{41}$ Such recommendations demonstrate the considerable faith placed in this therapy. As Gail Kern Paster records, many medical writers, well into the eighteenth century, conceived of the circulatory system as moving blood only slowly around the body. ${ }^{42}$ In redress to the blockages and stagnation thought to result from this state of affairs, the black blood which medical practitioners often claimed they could see collecting around tumours was supposedly removed by phlebotomy. Bleeding from the haemorrhoids or feet was believed to draw blood away from the cancerous areas of the upper body, starving the tumour of atra bilis. Opening the ankle (saphaena) vein in particular was also believed to redress the humours by provoking menstruation (and to procure miscarriage: an action linked pragmatically and figuratively to expelling the mis-conception of a cancerous tumour). ${ }^{43}$ As in the case of digestive purges, however, this treatment was not without its dangers. Browne's text contained a stark warning about letting blood around the area of a tumour. 'I have more than once observed in my Practice', he asserted, 'that letting the Patient Blood in the same Arm... on that side the Cancer is fixt, that new Cancers have readily been bred thereupon, and which have many times been more malign, and much worse than the former'. ${ }^{44}$ If phlebotomy had the power to move good blood into the area of a tumour, it also had the potential to move corrupting blood into other parts of the body, prompting what we now call metastasis. Medical practitioners also realised the risk posed to a patient's already failing strength posed by bleeding, exhorting readers to 'be cautious' and only let 'as much as the patient can suffer'. ${ }^{45}$

While it presumably deterred some patients, the 'suffering' involved in being bled may be viewed as integral to the perceived efficiency of the procedure as therapy for cancer. In contrast to the unbidden menstrual 
bleeding that signalled 'woman's inability to control the workings of her own body', Paster argues that 'the control of blood and bleeding exemplified by the phlebotomist's art becomes a key determinant of agency and empowerment' among both sexes. ${ }^{46}$ Indeed, much of the bloodletting carried out during this period was self-prescribed as a prophylactic, with wealthy individuals summoning the phlebotomist or barber-surgeon at certain times of year, or whenever they felt themselves 'plethoric' ${ }^{47}$ Even if bloodletting was not the patient's own suggestion, it was a procedure with clear, explicable logic for those familiar with the basic principles of humoralism. ${ }^{48}$ While cancer was often frustratingly mysterious in its causes and progress, bleeding offered patients the chance to control their bodily substance in a way that was tangible and visible.

Prescriptions for controlled diets, calm and quiet activities, medicinal purges and bloodletting were among the most common recommendations to appear in medical texts discussing cancer during the early modern period. As we have seen, they held considerable appeal, apparently undiminished by their potential to cause discomfort or even physical harm. Largely self-directed, cures based around regimen offered therapies that were readily understandable to patients, with medical practitioners possessing specialist knowledge - the best places from which to bleed, for example - but no basic insights into the procedures which were not virtually common knowledge for a population steeped in Galenism. Moreover, these cures were, to some extent, tailored to each patient's constitution. As Eve Keller describes, purging, phlebotomy and dietetics were all embedded in a discourse at once holistic and individualistic: holistic, because it foregrounded the interaction of self with environment; and individualistic, because it emphasised the uniqueness of each patient's constitution. ${ }^{49}$ Nonetheless, there were downsides to such therapies. Diets, purges and bleeding were 'catch-all' cures, designed to redress humoral imbalance and thus heal the whole body including the tumour, rather than to target the cancer specifically. For patients battling malignant tumours, searching for a definitive cure, this was often not enough. They sought more radical means, and in the thriving medical marketplace of early modern England, they found many sources willing to supply them.

\subsection{Plantain and wolves' tongues: herbal and animal remedies}

Pietre's letter to Fernelius advocated, as we have seen, the regulation of diet and lifestyle above all else. The medical practitioner's first concern, 
he argued, should be to redress the unbalanced humours which afflicted the whole body, effectively to starve the cancer of the atra bilis upon which it was founded. Having achieved this, however, Pietre also recommended applying a more specific cure. 'I conceive you ought to deal very gently with [the tumours]', he wrote:

nor must you use strong softners or digesters, least they grow worse, but gentle ones, such as is an ointment made of a little diacalciteos dissolved in juice of Plantane and Nightshade, al beaten together in a laden [leaden] morter. ${ }^{50}$

As cures went, this ointment was among the simplest, consisting of three basic ingredients. 'Diacalciteos' most likely refers to chalcitis, an oxide of iron commonly used in medicines of the period. Plantain and nightshade were common plants with respectively soothing and poisonous properties. Finally, the leaden mortar imparted some of its toxicity to the finished mixture. Despite its ingredients, however, Pietre's scant description implied that this was a 'gentle' remedy, perhaps temporarily alleviating pain in the affected area through the mortifying effects of nightshade. Most telling is Pietre's caution to his colleague: 'nor must you use strong ... digesters, least [the tumours] grow worse'. In this statement is contained the weight of a belief held by dozens of practitioners treating cancer, that aggressive therapies for the disease caused them to grow worse as if in an act of rebellion.

Pietre's fear can be traced back at least into the sixteenth century in English medical texts, and remained current well into the eighteenth. Barrough's 1583 The Method of Physick, for example, exhorted the reader to 'make choice of those medicines, which are of a meane force, and of a gentle qualitie'. ${ }^{51}$ His recommendation was explicitly tied to a conceptualisation of cancer which imagined the disease in anthropomorphic terms; Barrough believed that the malignitie of the evill through ... vehement medicines is stirred, and provoked, and made more fierce and savage'. ${ }^{52}$ Similarly, in 1651, Nicholas Culpeper's popular Directory for Midwives noted that cancer 'hath a peculiar malignity, which is fermented and mad[e] worse with Emollients and suppuraters' ${ }^{53}$ Imagined as semi-sentient, the capricious, ill-tempered cancer demanded to be only 'softly medled with' ${ }^{54}$ How exactly medical practitioners and patients believed that these medicines did 'meddle with' the disease is often unclear. Ingredients for such 'gentle' prescriptions were widely varied, frequently including plantain, rose oil or water, borage, honey, lead, alum, henbane and nightshade. ${ }^{55}$ Many medical writers, 
and in particular the writers of household receipt books, recorded these components, and the method to make their medicine, with no other comment attached than the ubiquitous 'est probatum' ('it is proven'). What is evident, however, is that there was no single cancer-curing herb included in these remedies. Rather, combinations of ingredients were chosen to combat the cancer through a mixture of symptomatic relief and redress of the atra bilis which caused the disease. Plantain, for example, was held by Culpeper's English Physitian to be a plant of such general usefulness that 'there [is] hardly a Martiall Disease but it cures', and was deemed particularly good for quelling fluxes and easing pain and inflammation, all features of cancerous disease. ${ }^{56}$ Roses were likewise credited with a myriad of healing properties, including reducing inflammation, purging choler and strengthening the vital organs. ${ }^{57}$ The seemingly counterintuitive inclusion of toxic plants such as henbane and nightshade into cancer remedies was believed, when applied correctly, to assuage pain and swelling. ${ }^{58}$ Balancing so many different properties, such remedies could be incredibly complex to prepare, with one cure from Elizabeth's Godfrey's 1686 receipt book listing 42 separate ingredients. This lengthy process, however, was deemed worthwhile when it seemed to produce results: recording the receipt, Godfrey noted that '[this] is the best was ever found out ... cour'd Mrs Finches maide'. ${ }^{59}$

Although in general it was the combination of ingredients which made these remedies specific to cancer, there was one notable exception. Animal products, including various kinds of fat and dung, were common in a range of medicaments for various diseases and were accordingly used in ointments and unguents for tumours. In remedies for cancer, however, some creatures - crabs, certain arthropods (mainly woodlice and centipedes) and worms - were found with a far greater frequency than elsewhere. Pechey, Barbette and Paré were among the many prominent early modern medical practitioners who included powdered crab in their remedies for cancer. ${ }^{60}$ Furthermore, they drew upon a long therapeutic tradition. Michael B. Shimkin identifies the ingredient as used similarly during the 'dark ages', while A. Kaprozilos and N. Pavlidis list crab as a main ingredient in plasters and ointments for cancer in ancient Greek texts. ${ }^{61}$ The inclusion of crab in cancer remedies was not explained or justified in the texts, leaving us to speculate as to its supposed utility. Given the close association of the crab with cancer, however, it seems likely that crab-based remedies were believed to work on the principle of 'like against like'. ${ }^{62}$ This principle is more obvious in relation to the inclusion of less common 'like' ingredients in cancer cures. The German physician Oswald Gabelkover, for example, advised 
in the late sixteenth century that '[f]or the gnawing Wolfe, or Canker' one should ' $\mathrm{t}$ ] $\mathrm{ake}$ a Wolves tunge, drye it, and beate it to poudre', before making it into a plaster with honey, and then 'wash the disease with wine \& strewe of the poudre of the Wolves-tunge therein till such time it be cured' ${ }^{63}$ The difficulty presumably involved in procuring a wolf's tongue testifies to the power it was believed to possess against cancer, also known as 'the wolf'. Belief in the efficacy of 'like against like' is even more visible in this 1651 account, in which a medical practitioner used a variety of 'worm' in medicine to expel the worm of cancer:

A Certain Emperick did help many cancers, in divers people (that were troubled with them) after this manner. He took certain worms, called in latine Centumpedes, in english sows: they are such as lie under old timber, or between the bark and the trees. These he stamped, and strained with ale, and gave the patient to drink thereof morning and evening. This medicine caused many times a certain black bug, or worm to come forth which had many legs, and was quick, and after that the cancer would heal quickly with any convenient medicine. ${ }^{64}$

Once again the powerful 'like' ingredient required no additions, no combination with other substances to work its cure. The sole purpose of the ale seems to have been as a medium in which the 'Centumpedes' might slip down more easily.

Medicines containing parts of worms or wolves highlight the slippage that occurred in early modern medical discourses between viewing those creatures as apt analogies for cancer and imagining them to be physically involved in the disease. Being less common ingredients than crab, they tended to be discussed at greater length, illuminating more clearly the principles behind these 'like cures like' remedies. First, the 'stamping', crushing or burning of the animal material could be seen as an act which transferred negative feelings about the tumour onto its substitute in the medicine. That is, the annihilation of the crab, wolf or worm ingredient might symbolically stand in for, as well as physically effecting, the annihilation of the zoomorphised tumour. Secondly, the spatial emphasis in Border's account implied a different kind of substitution. The worm or 'centumpede' was taken from its dwelling place between the bark and trunk of a tree; a place which, appropriately, recollected the subdermal or sub-cutaneous positioning of many tumours. Being bent to the purposes of the empiric through stamping and straining with ale, the reformed 'centumpede' appeared to drive out the many-legged 'bug' from the body, as if only one could occupy that space at any moment. 
The harmful cancer-worm was replaced with a similar creature which was beneficial to the patient and, crucially, controllable by the medical practitioner.

Attempts at curing cancer with crabs and worms illustrate the degree to which many pharmaceutical cures tended to treat the cancer as a discrete entity, rather than redressing the humoral balance of the whole body - despite the fact that the authors of these cures did not identify themselves as interested in ontological disease models in an academic sense. This was partly a product of cancer's imaginative construction as ontologically independent of the cancer patient. Such cures were also products of the expanding medical marketplace. As Harold Cook has pointed out, demand for new goods in this period meant that practitioners could make more money selling cures for specific diseases than they could balancing the complexions of a few wealthy patients. ${ }^{65} \mathrm{In}$ this increasingly competitive environment, a gulf emerged between writers - often university-educated, licensed physicians - who emphasised the difficulty of curing any established cancer, and other medical practitioners, sometimes advertising in newspapers or pamphlets, who promised a quick, cheap and painless cure. Though licensed medical practitioners undoubtedly have the loudest voice in surviving historical documents, there nonetheless remain tantalising glimpses of the prestige achieved by some so-called empirics. In 1714, for example, Daniel Turner described one 'famous Cancer doctor' as a 'villainous empiric', indicating that one might specialise in this disease as other unlicensed practitioners did in bone-setting or cutting for the stone. ${ }^{66}$ He advised those who had cancer that they should on no account

[1]ist[en] after a promised Cure by cosening Quacks, or Cancer-curing Pretenders, who, to my Knowledge, have hasten'd great Numbers of People miserably to their Graves, who might otherwise (and that very tolerably) have spun out a much longer Thread and have kept under this really (so far as I know of Surgery) incurable Distemper. ${ }^{67}$

For their part, the 'Cancer-curing Pretenders' attracted 'great Numbers' of people to their services by promising what Turner felt he could not. Advertisements for internal medicaments or gentle ointments to cure a cancer quickly and painlessly were frequently accompanied by testimonials from satisfied customers enjoying newfound 'Health and Ease'. ${ }^{68}$

Why did these advertisers - some, licensed physicians, but many, apothecaries or 'unauthorised' practitioners - give a prognosis so much more optimistic than that found in medical textbooks? There was 
certainly profiteering at work and the fact that such sources are self-selecting. Nobody advertises that they cannot cure a disease. Nevertheless, the fact that these drinks or salves were frequently touted as 'universal', curing everything from dropsy to gout, is also instructive. Customers who purchased one of these cure-alls probably did so of their own volition or on recommendation from friends and family, since medical practitioners were understandably reluctant to send business to their competitors. Therefore, they were less likely to have received a formal diagnosis of cancer, such as an examining physician might provide. Their disease may have been less advanced, and they may have been less concerned with whether it was a 'true' cancer (as opposed to a cyst, scirrhus or mastitis) than whether the cure-all managed to relieve it. This also seems to be the case for writers of household receipt books, who had little to gain financially from insisting that their cancer remedies were 'probatum'. In certain household receipt books, both topical and internal remedies promised to 'infallibly cure' cancer, to cure it 'tho it be eaten to the Ribbs' or was 'as bigg as a Goose Egg' ${ }^{69}{ }^{69}$ These remedies were often similar - sometimes identical - to those contained in printed medical textbooks, yet their writers seem to have been far more optimistic about the likelihood of their producing a full and lasting cure. Once again, the reasons for this may be ones of how the disease was conceptualised and diagnosed. By and large, receipt book writers did not give cancer the special treatment it received in medical textbooks. Often conflated with other diseases such as King's-evil or scirrhus, there was no mention of cancer being 'evil' or 'rebellious' in these pages, of its peculiar appearance or rate of growth. Cancer appeared only as one more illness to be cured.

Across medical genres, physicians, apothecaries, empirics and practitioners of household physic offered a wide range of animal and vegetable remedies for cancerous tumours. Equally, they gave substantially different promises about how effective those remedies might be, based in large part on how narrowly 'cancer' was defined. While certain receipt book writers promised almost miraculous cures, others advised that 'we shall deale sufficiently in this case' if able to 'stop and hinder [tumours] growing and encreasing.$^{\prime 70}$ Though their prognoses might differ, however, these remedies often shared a few key ingredients - some plants designed to strengthen and soothe, others which were extremely poisonous and animal ingredients from creatures felt to be literally or rhetorically aligned with cancer. This reflected the way in which cancer was conceptualised as both of and hostile to the body. In writing about these remedies there was less emphasis on rebalancing the whole body and much more on 
addressing the tumour as a hostile entity. Concomitant with this shift was a move away from self-prescribed and domestic physic toward professional intervention, and an increased emphasis on the fragile reputations of those who provided such intervention.

\section{3 'Extreame remedies are to be used, against extreame diseases': pharmaceutical caustics and the first chemotherapies ${ }^{71}$}

In printed medical textbooks, practitioners repeatedly emphasised the double bind which they felt that cancer presented. They widely maintained the conviction that harsh remedies exacerbated cancers. However, they often added to that conviction another, proven by bitter experience - that gentle remedies failed to touch the disease at all. This conundrum was nothing new to writings on cancer, yet it persisted over the entire early modern period. In 1571, for example, a translation of the work of fifteenth-century Italian surgeon Giovannida Vigo explained that remedies with 'a weake and feeble power ... worke no effect (as Galen saith) but are easily overcome' ${ }^{72}$ However, 'strong and mightie' medicines made the cancer-causing humours 'more obstinate and more hard to be dissolved and discussed'.$^{73}$ Over 120 years after this publication, a translated text by the French physician and surgeon Paul Dubé made an almost identical argument, asserting that cancer possessed 'so odd a Nature, that it does not hearken to gentle Remedies, and grows worse by the use of violent ones', while Culpeper's immensely popular $1651 \mathrm{~A}$ Directory for Midwives similarly complained that 'mild Medicines are not felt, and strong, exasperate'.${ }^{74}$ Each of these writers construed cancer in anthropomorphic terms, as having a will somehow independent of the sufferer. Cancer, they agreed, was resistant, stubborn and exasperating for medical practitioners, to say nothing of their patients. ${ }^{75}$ This presented a serious problem. As Paré asked: 'seeing it refuseth gentle medicins ... and is not to be cured, but with strong medicins: which neverthelesse make it worse \& more fretting, is [it] not to be deemed incurable? ${ }^{76}$

For many medical practitioners, the answer to Paré's question was a simple 'yes', and they advised that treatment should be restricted to palliative care, in order to spare the patient further suffering. For others, however, this double bind did not signal the end of all curative efforts. If cancer ignored gentle remedies and reacted against stronger ones, the solution was to employ an arsenal of the era's most powerful medicaments, to deal a blow the disease could not resist. Ideas about what kind of substance might be best used to this end naturally varied widely. 
In many cases, it was a matter of adjusting so-called gentle remedies by adding components such as alum, a potassium compound. ${ }^{77}$ Other medical practitioners and domestic healers left the composition of their remedies unchanged but applied them at extremes of temperature, usually very hot. ${ }^{78}$ The most notorious strong remedies, however, were those which were intrinsically and powerfully toxic. Providing the focus for the remainder of this chapter, they are perhaps the first recognisable chemotherapies - arsenic and mercury.

The Oxford English Dictionary defines chemotherapy simply as 'treatment with specific chemical agents or drugs', but the word has become synonymous in the past 50 years with a particular kind of pharmacy which visibly poisons the body in order to kill a cancer therein. ${ }^{79}$ This rationale - poison against poison - was also at work in the early modern use of heavy metal and metalloid treatments for cancer. Medical texts of various kinds show that mercury and, to a lesser extent, arsenic were employed throughout the early modern period, primarily by physicians, but also occasionally by domestic receipt book writers or itinerant medicine-sellers. Those using mercury, for example, included noblewoman Elizabeth Grey, who used 'four pennyworth' of the substance in her recipe 'To make a Strong water good for a Canker, or any old Sore, or to eat any lump of flesh that growth $[s i c]{ }^{8}{ }^{80}$ Practitioners varied in their explanations of just how mercury could remedy cancers. In therapies for venereal pox, it had long been accepted that the profuse sweating and salivation caused by mercury helped to expel bad humours from the body. ${ }^{81}$ In texts on cancer medicine, however, this logic was less evident, and there was more emphasis on how the substance acted on the tumour or ulcer itself. In 1684, a translated work by the Swiss physician Théophile Bonet proposed that 'Leaden Plates smeared with Quick Silver, are a kind of Alexipharmack [antidote to poison], whereby the evil disposition of Malignant Ulcers is subdued and spent' ${ }^{\prime}{ }^{82}$ At other points in mercury's long therapeutic history, medical writers recognised the toxicity of the metal as intrinsic to its effectiveness. In 1571, for example, Vigo extolled the virtues of mercury as not only a cancer cure in itself, but also an 'incredible' painless way to kill off any remaining 'superfluous' flesh left after cutting away a tumour. ${ }^{83}$ In both models, the virtue of mercury in cancer cures was that it was powerful enough to 'subdue' the normally rebellious disease. Cancer ate the flesh; mercury, too, was capable of 'eating' unwanted or 'superfluous' flesh, demonstrating that it could match the strength of a malignant tumour.

Unlike mercury, arsenic powders and ointments were used more exclusively by professional medical practitioners and are not mentioned 
in household receipt books. Nonetheless, this too was a substance with a long therapeutic heritage. For instance, The Surgery of Theodoric, c.1267, recommended 'arsenic sublimate' as a way to mortify cancerous flesh so that it could be sloughed off. ${ }^{84}$ Medical practitioners of the seventeenth century treated the substance in much the same way, with Culpeper, Riverius and Read among those authors who included arsenic, often in a 'sublimed' (washed) form, in their published cancer remedies. ${ }^{85}$ On the continent, Anne of Austria (1601-66), who underwent various gruesome procedures in the hopes of curing her breast cancer, was treated with arsenic regularly between August 1665 and January 1666, with physicians applying arsenic to mortify the flesh and then cutting it away. ${ }^{86}$ Across the late sixteenth, seventeenth and eighteenth centuries, the appeal of arsenic seems, like mercury, to have centred on its 'eating' qualities, which matched those of the cancerous tumour. Read's 1650 Workes recorded that 'superficiall' tumours could be 'eaten out' with arsenic, while in 1597, Lowe noted that arsenic possessed 'force to consume the evill humor'. ${ }^{87}$

Mercury and arsenic were material actors of such force that they, unlike diets, purges and herbal drinks, seemed able to match the ferocity of the cancerous tumour. Their ability to consume flesh mimicked that of the disease to be overcome, promising to expel cancer from the body in much the same way that medicines of worms and crabs seemed to work: 'like against like'. Since, unlike many medicinal ingredients, arsenic and mercury could not be used as foodstuffs, one might also view them as having had an additional psychosomatic force. These substances were firmly stamped 'medicine', and appear to have been well known as among the strongest remedies to be had. With this potency, however, came some drastic and dangerous side-effects. For every writer who recommended mercury and arsenic there were several more who warned in vehement terms that these substances were dangerous to the practitioner's reputation and to the patient's life. The unpleasant effects of mercury in particular were common knowledge among medical practitioners and many lay people, even cropping up in dramatic works such as Shakespeare's Hamlet (1.5.66-75) ${ }^{88}$ Believed to act as a powerful purgative, 'salivation' treatment was associated with a raft of physical and neurological disorders, as described by Siena in his study of London's 'foul wards'. As well as excessive salivation, which was supposedly beneficial, '[ $t$ ]he toxicity of ... prolonged regimens of a heavy metal usually produced dreadful side effects. Patients frequently suffered internal pain, intense nauseam and permanent damage to their mouths including loss of teeth, gum damage, and the complete loss of the uvula' ${ }^{89}$ 
It is unclear whether mercury treatment for cancer was as prolonged as that for pox, which could last five weeks or more. ${ }^{90}$ It seems unlikely that patients with advanced cancers could have survived such a regimen. Nonetheless, even those who advocated mercury treatment admitted that the substance could be dangerous. Reporting on the case of a woman with breast cancer, Bonet recorded:

The Physician that was consulted ordered a Plate of Lead to be applied, and every other day to smear it lightly with quick silver ... But through the carelessness of those that lookt after her, the Plates did more harm than good. In the mean time the Canker encreased, and came to Suppuration; therefore the use of the Plate was laid aside. The Swelling broke of itself, and her torments ceased a little; but by and by they returned more violent and pungitive, the Canker encreaseing in all its dimensions. It deserves admiration, that the Mercury which was formerly imbibed from the Plate, should drop so visibly, and in a pretty quantity out of the Carcinoma, which shaded the adjacent parts with its shining, nay, and sweat at the shoulders through the whole skin. ${ }^{91}$

In this case, the parallel properties of mercury and cancer turned against the patient. The 'eating' mercury failed to consume the cancer, but led to 'suppuration' and allowed the cancer to keep growing, setting the stage for the onset of a cancerous ulcer. Worse still, mercury then spread through the body, becoming visible at its surface in a way which brings to mind cancer's much-discussed propensity to remain 'secret' before suddenly 'discovering' itself. Altogether, the account demonstrated vividly the dangers attendant on introducing a substance to the body which might exceed the practitioner's control.

If mercury was a source of anxiety, arsenic caused outright panic among some early modern medical practitioners. Unlike mercury, there is little evidence for the substance having been notorious in popular culture, but medical writers recorded numerous instances of arsenic's fatal side-effects, often in lurid terms. ${ }^{92}$ The expanded 1712 edition of William Beckett's New Discoveries tempered acknowledgement of the popularity of arsenic among some medical practitioners with a striking warning from personal experience:

This Powder [of Arsenic] I apply'd to a Cancerated Breast of a Woman, under thirty Years of Age, after having made a Sore by applying one of the milder Causticks, the night it was made use of, it caus'd a great 
deal of Pain, and the next Day, the Breast appear'd very much tumefied and inflam'd... in short for fifteen Days she was not free from pain, she had a Fever, was attended with frequent Vomitings, Faintings, and several other Disorders. I cou'd afford her but very little Relief by intervals...nor was it in my Power to remove the Dressing, it adhaered so fast to the Sore. There was a discharge of a bloody serous Juice for twelve Days in a moderate quantity, after which the matter thicken'd, and it began to smell somewhat offensive, at the end of fifteen Days the Dressing drop'd off, and with it came away about two Ounces of the cancerous Mass. The Reader may easily imagine that making so small a progress in such a time, and that at the Expence of so much Pain, I cou'd easily prevail with myself to desist from the undertaking, for the second Application wou'd have been attended as the first, which to any Person that entertains such a concern for his Patients as he ought to do, must be very fatiguing. ${ }^{93}$

In this account the ability of arsenic to redouble the disease's original symptoms was again apparent, with the medicine producing pain, 'serous Juice' and stench, as well as 'adhering' to the body in much the same way as the obstinate, crab-like tumour. Even more distressing for Beckett was the immense pain to which the therapy put his patient. Not only 'fatiguing', this effect was sufficient for Beckett to abandon the use of arsenic altogether, stating that 'we can't say, but there are many Cancers that may be cur'd by Causticks, but the Person that is to undergo it, may very well answer... The Preservation of Life would be too dear bought at the Price of so much Pain'.${ }^{94}$ Beckett's account was far from isolated. Only a decade earlier, Browne had likewise attested that arsenic could cause 'Faintings, Swooning, Fever, Madness' by sending forth 'malign ... vapours' to the heart or brain even when it was applied to the arms or legs. ${ }^{95}$ Like mercury, arsenic threatened to break its bounds, taking over the body in the same manner as the cancer itself. At the mildest end of the cancer treatment spectrum, dieting and purging had treated a patient's whole body and often their mind. Arsenic and mercury now targeted the cancer in isolation. They were clearly far more potent treatments, but they could kill the sufferer before they quelled the disease.

Browne's warning of the 'great injury' wrought by arsenic, as well as Beckett's 'fatigue' at witnessing his patient's suffering, points to an uncomfortable awareness among medical practitioners of the risks to which they exposed themselves as well as their patients when they administered dangerous remedies. In the 1684 translation of Bonet's 
Guide to the Practical Physician, for instance, the fate of a rival practitioner's patient was described thus:

I have observed [septics], especially Arsenick, and sublimate in a greater quantity, and not tamed, applied to Ulcers near the heart, as to a Cancer in the breast, that they once carried off a Woman in 6 days: About three hours after the Powder was strewed on her Breast, she just as if she had swallowed it, was taken with a Shivering, then with a Vomiting, and frequent Faintings, with a languid Pulse; which symptomes, encreasing by degrees, her extreme parts growing cold, and her Face and whole Body swelling beyond measure, she was miserably murthered. ${ }^{96}$

The 'murther' Bonet described demonstrated forcefully the moral predicament facing those who administered arsenic or similarly toxic medicines. Although the substance held some potential to cure an otherwise fatal disease, it also presented an imminent danger to the life of the patient. Moreover, Bonet went on to name four practitioners who used arsenic in their cancer medicines, and were therefore to be avoided. ${ }^{97}$ Being associated with arsenic treatments could therefore be economically as well as morally dangerous in a marketplace where the consumer at least, if London-dwelling and affluent - had various practitioners seeking their custom, and in which physicians accused of malpractice could find themselves fined or even imprisoned. ${ }^{98}$ In this climate, why did both patients and practitioners continue to pursue such dangerous and toxic treatments?

The answer to this question may partly be found in the diaries of Reverend John Ward, with which this book opened. Recording a physician's prescription of 'desperate' cordials to a seriously ill patient, he recalled this maxim: 'With it they may die, but without it they will die' $^{\prime}{ }^{99}$ One must remember in the case of dangerous medicines (and in the following chapter, of surgery), with what stakes patients were gambling. Cancer, as we have seen, was firmly established in the popular consciousness as a cruel and fatal disease, such that in many cases patients must have viewed the use of extreme pharmaceuticals as risking possible swift death, with the chance of cure, against certain, perhaps slow death, with no chance of reprieve. In addition, mercury and arsenic, hazardous as they undoubtedly were, may still have seemed a favourable alternative to the other means by which a cancer could be 'consumed': namely, cautery with burning irons, or surgery. Patients making the seemingly extraordinary choice to be voluntarily poisoned 
by mercury and arsenic may have exhausted more gentle means, and experienced their options as a matter of choosing the lesser of two evils. Furthermore, scholars of early modern medicine suggest that the painfulness of certain therapies may actually have been taken as a marker of their effectiveness. Michael Schoenfeldt, for instance, emphasises the centrality of pain to early modern experience, including the belief in pain as a form of divine punishment. ${ }^{100}$ Writing on medical metaphors in moral theology, David Harley similarly notes that whilst believers were not discouraged from seeking medical relief from illness, painful medical treatments were frequently compared to confession or repentance. ${ }^{101}$ As with the administration of purges or burdensome regimen, going through painful remedies might be construed as penance for one's inevitably sinful nature, or as a kind of labour by which to expel the disease from the body. As Porter argues, '[T]he ferocious painfulness of a treatment might even work in its favour - the earnest of its efficiency lay in its bite or sting' ${ }^{102}$

The factors which made medical practitioners stake their reputations, and thus their livelihoods, on arsenic and mercury as cancer cures are less obvious. Although they had much less to lose than their patients, those administering extreme pharmaceutical remedies also had less to gain. There is little to suggest that physicians or medicine-sellers built lucrative commercial reputations based on curing cancers with these chemicals. On the contrary, they were likely to be decried by their fellows. One component in encouraging medical practitioners to use arsenic and mercury despite the risks may well have been compassion for the suffering of their patients. Surgeons frequently stated that they were induced to perform dangerous operations by the pleas of the sick party, and it seems reasonable to suppose that physicians were subject to the same pressures. In addition, of course, they must have been aware that should they refuse to administer certain therapies, a patient might simply go elsewhere. The language in which practitioners describe their use of mercury and arsenic may also offer clues as to why they persisted in this dangerous course. Where dietary cures involved the treatment of the whole body, and the active participation of the patient, cures by arsenic and mercury were often framed as attacking the cancer in isolation from the rest of the body. For example, describing the use of arsenic powder by 'Fuchsius', Browne noted that

he applied [arsenic powder], upon which, if the Cancer did not grow more angry the $3 \mathrm{~d}$ day after, he declared the Cancer curable; and if it grew better, the Powder was to be kept on for 30 days, in which time 
it would be eradicated from the very roots, and they fall off of themselves; and if any part of them did continue adhering, he usually cut it off with his Knife. ${ }^{103}$

Despite the considerable pain this must have caused Fuchsius's patients, they were virtually invisible in this account, having neither voices to assent or protest, nor any discernible role in their own treatment and recovery. Tellingly, it was the cancer, not the patient, which was deemed 'curable', but which could become anthropomorphically 'angry' upon application of the powder. The ferocity of the arsenic powder, which caused tumours to 'fall off', is equally telling. Chosen because its 'eating' properties matched that of the malignant cancer, one may see the curative agent in these accounts as an extension of the practitioner's own strength. Indeed, even as he warned of the difficulty of employing chemical caustics, Wiseman reported that they do your work in less than an hour'. ${ }^{104}$ Just as cancerous disease was construed in zoomorphic and anthropomorphic terms, portrayals of potent cancer remedies aligned the substances with a sentient agent - in this case, the ministering physician.

Arsenic and mercury were not the most commonplace remedies for cancer in the early modern period. In the imaginations of medical writers and their audiences, however, they loomed large, as much for their dangerous side-effects as for their potential to cure. Many medical practitioners, and presumably their patients, were nervous about using substances which caused such drastic collateral damage. For some, the risks seemed unjustifiable, and edged the physician or apothecary over the tenuous boundary between healing and harming, at which point they became no better than 'murtherers'. However, many others continued to employ heavy metal and metalloid ingredients in their cancer remedies. The appeal of such potent substances was of a piece with the discursive estrangement of patients from their alien, invasive tumours. In the battle against cruel, 'rebellious' cancers, arsenic and mercury were powerful armaments.

\section{Conclusion}

In the diverse accounts of early modern cancer medicines, patients' voices are conspicuously absent. An appropriate postscript to this chapter is therefore provided by the poignant but frustratingly incomplete record of one woman's experiences with cancer physic, as told by her uncle Henry More, in a series of letters written to Lady Anne 
Conway between July 1674 and January 1676. More and Conway were in correspondence on a number of matters. However, More sought Conway's advice in particular regarding his niece 'Mrs Ladd', who was suffering from breast cancer, because of Conway's close acquaintance with 'Monsieur Van Helmont' (son of Jean Baptiste Van Helmont). Via Conway, Van Helmont sent prescriptions to More and Mrs Ladd which are not detailed in the surviving documents, but, judging by their effects, contained some potent chemical and organic components.

Beginning optimistically, More's letters described his hopes of a cure for his niece, and told how he had informed her of Van Helmont's 'fame' in Europe, hoping that 'it may contribute to the efficacy of the medicine'. ${ }^{105}$ Within a month, however, Mrs Ladd began to experience the side-effects of her treatment. Her physician informed More that the medicine

produced no alteration in her till the Sunday following, she has been these three dayes ill at her stomack, hot and thirsty, with frequent shootings in her breast, and not only on the cancer'd part, but likewise round about it there are many little angry pustulats, first red, afterwards maturated on their heads. ${ }^{106}$

Nonetheless, seeing some softening of the tumour, Mrs Ladd was persuaded to carry on. Over the coming months, she repeatedly complained of pain and fever, sometimes declining to take the remedy, then consenting to its use once more. In December 1674, More wrote to Conway:

I hear from Grantham also that my Neece make use againe of the Plaisters... But in a letter December 3 my Nephew writes thus, Though my sister be advised from ragley to proceed in the use of her plaister, yet I doubt she needs further advise what to doe; for besides the paine and disturbance it hath given her, it has much encreased the bignesse of the soar which is all in such fretting distemper. This makes me tell Dr Clark that he must judge upon the spot. And I beleeve he does not deele so openly with me as he should, out of a nicenesse to displease me, Because of my great opinion I have expressed of Monsieur Vanhelmont. So that I am something at a losse what to doe in the case and dare over sensibly presse the use of the plaister upon my Neece. For feare of the worst. ${ }^{107}$

Shortly after, he reassured his correspondent that 'what ever it be I shall account myself much obliged to Monsieur Vanhelmont for his good 
will. He did not pretend to ascertaine the cure at first. But seeing by this Medicine he had cured this kind of disease, I could not but take the boldnesse to desire him to try the successe of it on my Relation'. ${ }^{108}$ Mrs Ladd then disappeared from More's letters. When she reappeared in March 1676, it was for More to inform Conway that he was journeying to his niece's deathbed. ${ }^{109}$

More's letters provide the closest thing to a patient's account of pharmaceutical cancer treatments in this period and are a salutary reminder of the real sufferings behind textual representations of medicine. They also show the shifting relationships which cancer sufferers had to their physicians and other medical practitioners at this time. More, Mrs Ladd, and those around her were seemingly caught between a desire to acquiesce to the 'famous' physician, and conviction in their own observations, that the cancer was being exacerbated by his so-called remedies. Accordingly, the story of non-surgical treatments for cancer is a complex one. More than any other facet of the diagnosis and treatment of cancer, one might expect non-surgical treatments to show substantial change over time, influenced by the much-discussed rise of iatrochemistry in the later seventeenth century. The sources, however, give a more nuanced account. Medical practitioners may or may not have used mercury and arsenic with increasing frequency over time. Accounting for the bias toward the later part of the early modern period created by material factors - namely, the increased number of texts produced, and hence available to us today - it is difficult to see any conclusive evidence of a move toward these kinds of remedies. Certainly, neither medical practitioners nor patients of the seventeenth and early eighteenth centuries were prepared to abandon gentler prescriptions for regimen and medicines explicitly aimed at correcting the humours. Furthermore, the inclusion of mercury and arsenic cures in medieval texts prohibits us from imagining these substances as having been 'discovered' by Renaissance physicians, or taken up as a direct result of the rise of iatrochemical medical models.

What can be traced, however, are smaller-scale shifts in rhetoric and practice identifiable with the changing ambitions of both patients and those who treated them. Cancer was by no means the only intractable, fatal disease of the early modern period. It was, however, among those most vividly imagined in zoomorphic and anthropomorphic terms, a disease which was, as we have seen, both of the body and alien to it, which seemed purposely malign, evil and rebellious. As patients became increasingly pained and frightened by progressive cancers, it is little wonder that they sought remedies of increasing strength and 
complexity, tolerating the discomfort they evinced and even taking their suffering as signs of the treatment's efficacy. Significantly, one can also see in these discourses how, through the process of increasingly desperate cures, patients relinquished - or medical practitioners appropriated - authority over their bodies and what happened to them, a move concomitant with the construction of cancers as 'independent' from cancer patients. Adjustments to diet and regimen, the first recourse for most cancer patients, closely involved the sufferer in their cure, and were readily explicable in terms of a holistic humoral system. A little further along the treatment spectrum, medicines containing herbal and animal ingredients were increasingly targeted at the tumour, rather than the individual patient, allowing medicine producers to peddle 'onesize-fits-all' cures. The rhetoric which accompanied description of the harshest non-surgical cures, however, shows how the therapeutic landscape was shaped as much by language as by science or economics. With cancer constructed as evil, medical practitioners cast their own attempts to cure the disease as a battle of medical knowledge against a discrete, zoomorphic enemy. The diminished figure of the patient, therefore, made room for the confrontation between cancer and physician to be writ twice as large; a trend which would continue to develop in the agonising procedures of cancer surgery.

(c) (1) Except where otherwise noted, this work is licensed under a a copy of this license, visit https://creativecommons.org/version4 